IN SEARCH OF SECURITY:

ACCESS TO AFFORDABLE HOUSING AMONG IMMIGRANT WOMEN

WHO HAVE EXPERIENCED INTIMATE PARTNER VIOLENCE

by

Sadaf Grace Seifi, BA, Simon Fraser University, 2014

A Major Research Paper

presented to Ryerson University

in partial fulfillment of the requirements for the degree of

Master of Arts

in the Program of

Immigration and Settlement Studies

Toronto, Ontario, Canada, 2015

(C) Sadaf Grace Seifi, 2015 


\section{AUTHOR'S DECLARATION}

I hereby declare that I am the sole author of this Major Research Paper. This is a true copy of the MRP, including any required final revisions, as accepted by my examiners.

I authorize Ryerson University to lend this MRP to other institutions or individuals for the purpose of scholarly research.

I further authorize Ryerson University to reproduce this MRP by photocopying or by other means, in total or in part, at the request of other institutions or individuals for the purpose of scholarly research.

I understand that my MRP may be made electronically available to the public.

Sadaf Grace Seifi 


\title{
IN SEARCH OF SECURITY: ACCESS TO AFFORDABLE HOUSING AMONG IMMIGRANT WOMEN WHOHAVE EXPERIENCED INTIMATE PARTNER VIOLENCE
}

(C) Sadaf Grace Seifi, 2015

Master of Arts

Immigration and Settlement Studies

Ryerson University

\begin{abstract}
This paper presents insights into the lived experiences of immigrant women of varying degrees of immigration status, who have experienced intimate partner violence (IPV) and, as a result, have faced difficulty securing safe and affordable housing. The information was collected through 15 interviews with immigrant women as well as key informants who work with immigrant women. The study findings show that the needs are even more pronounced for immigrant women who face additional barriers such as lack of English/ French language skills, support systems, and financial means. Using an intersectionality perspective, this paper explores the ways in which a lack of adequate housing influences the safety and stability of immigrant women who have experienced IPV in Metro Vancouver.
\end{abstract}

Key Words: abuse; immigrant; intimate partner violence; housing; status; women/woman; and intersectionality. 


\section{ACKNOWLEDGEMENTS}

I would like to thank my supervisor Dr. Sepali Guruge, firstly for her support and feedback which was integral to the development of this project, and secondly for her motivation and instruction throughout my work as her research assistant. I also thank Dr. Margareth Zanchetta, the second reader, for her constructive comments.

I would also like to especially thank the participants who shared their stories of courage and resilience and have changed the course of their lives for the betterment of their children and generations to come. Their insights and experiences have greatly contributed to the foundation of this paper.

Finally, I am grateful to my family for their continuous love and support. 


\section{TABLE OF CONTENTS}

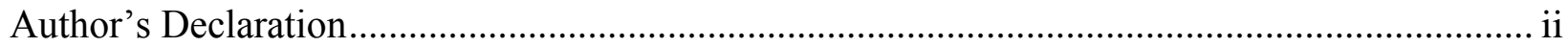

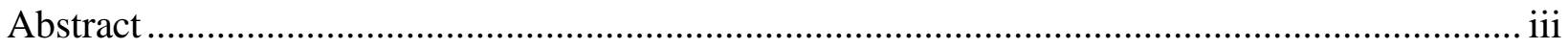

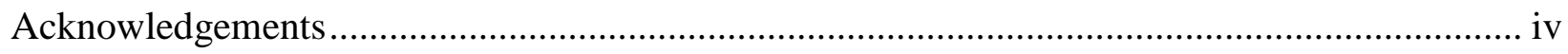

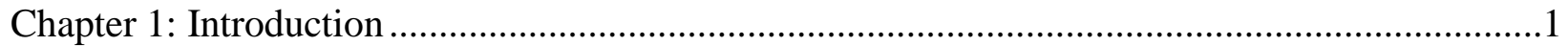

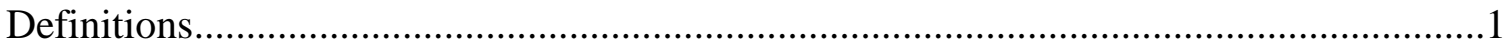

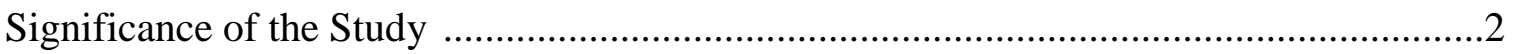

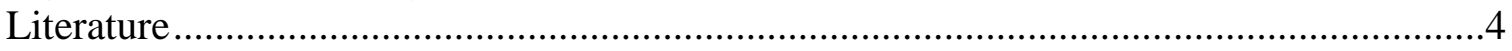

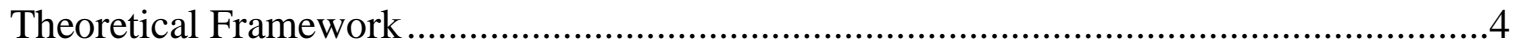

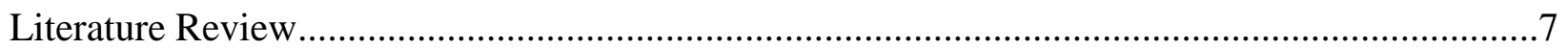

Intimate Partner Violence (IPV) Among Immigrant Women in Canada ..........................

Housing Situation in Canada ...............................................................................10

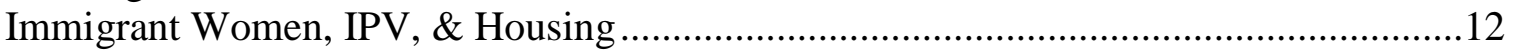

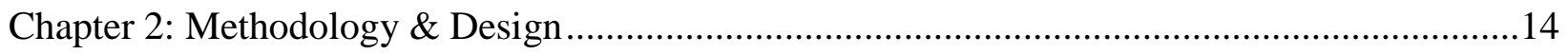

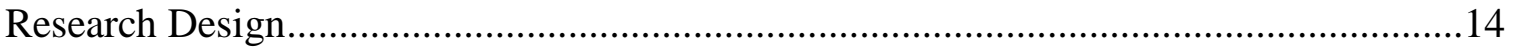

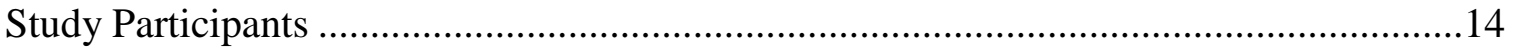

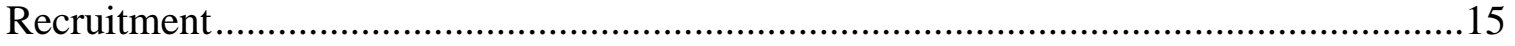

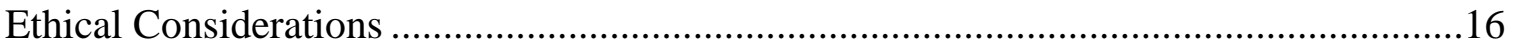

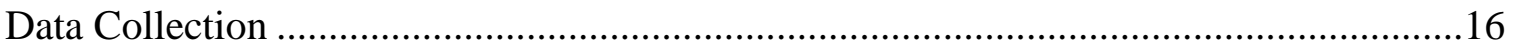

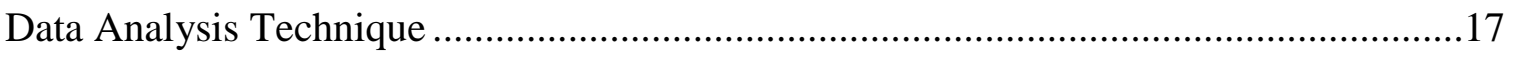

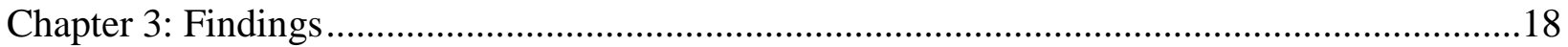

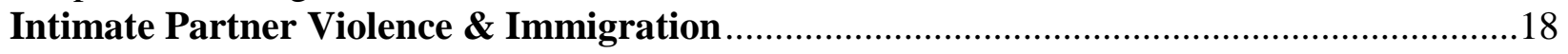

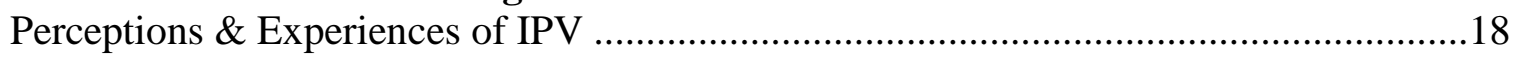

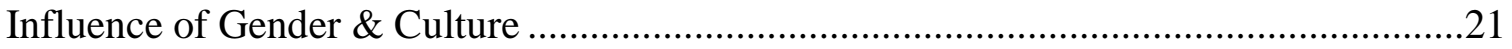

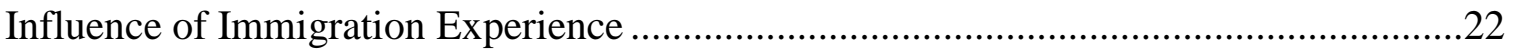

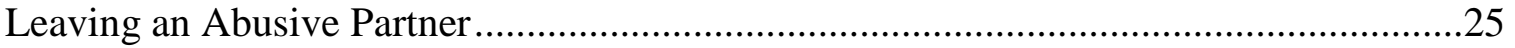

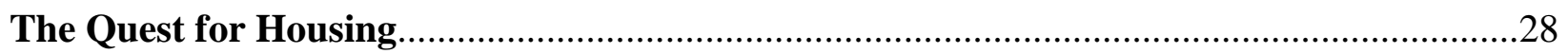

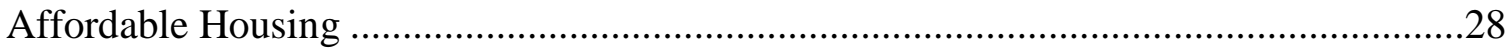

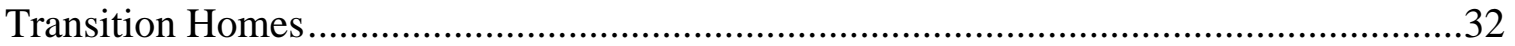

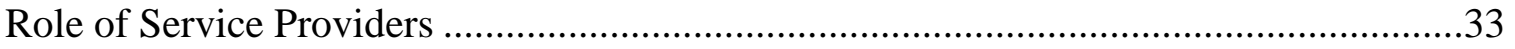

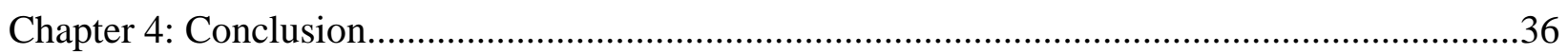

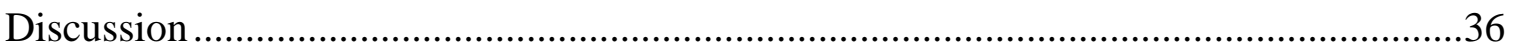

Systemic Causes of Housing Insecurity Among Immigrant Women .............................38

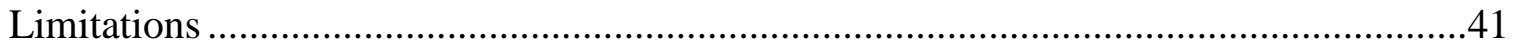

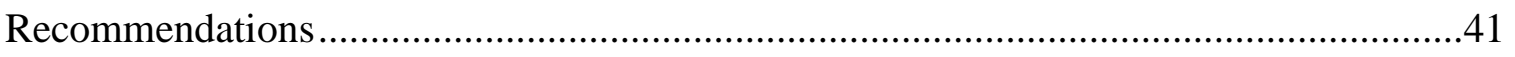

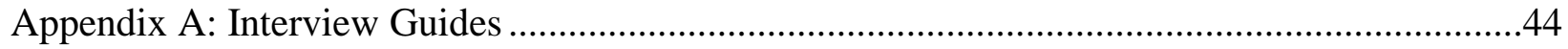

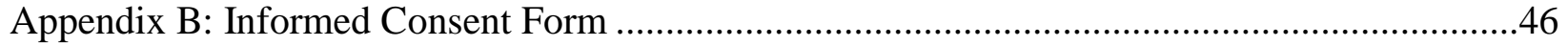

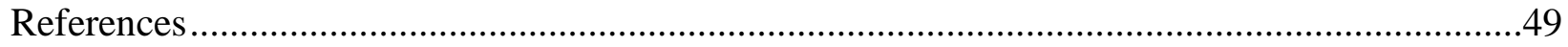


"The eradication of violence requires not only changes in law and policy, but more fundamental changes at the level of culture, attitudes and beliefs. Such changes must be grounded in the conviction that the equality of women and men is not only a goal to be achieved, but a truth about human nature to be acknowledged and embraced. The soul has no gender. The very essence of what make us human is neither 'male' nor 'female.' Conceived in this way, equality goes beyond a tally of resources or a set of social norms. It reflects the nobility inherent in every human being."

- The Baha'i International Community

57th Session of the Commission on the Status of Women, 2012 


\section{CHAPTER 1- INTRODUCTION}

\section{DEFINITIONS}

This major research paper will use three central terms: 'intimate partner violence', 'immigrant women', and 'housing' to examine the ways in which immigrant women who experience intimate partner violence access safe and affordable housing in the Metro Vancouver housing market.

Intimate partner violence (IPV) refers to the experience or threat of physical or sexual violence and/or financial or psychological/ emotional abuse by a current or ex-partner in the context of coercive control (Saltzman et al., 2002; Tjaden \& Thoennes, 2000). For the purpose of this research, "immigrant women" will refer to women born outside of Canada. This definition is used intentionally in this MRP in a broad sense in order to include long term residents, newcomers, refugees, temporary residents and people with precarious or no immigration status in the study. Though there is immense diversity within this group, it is their situation outside of the mainstream, experiences of migration and vulnerability within the immigration system that create similarities (Menjivar \& Salcido, 2002). As argued by Menjivar and Salcido (2002), 'pinpointing the commonalities in immigrant women's experiences with domestic violence allows for theorizing about the conditioning factors that shape these experiences and what strategies women use... [the] intent is not to undermine the heterogeneity of immigrant women across different cultures, even though the discussion will be centered on commonalities.' It is important to recognize 'individual characteristics of the immigrant groups and the context where they arrive that will qualify broad generalizations' (p.3).

The term "housing" refers to and includes several additional terms, which will also be used within this paper. First of all, affordable housing is housing that can be provided by any of 
the following: the City, government, non-profit, community and for-profit partners. Housing affordability can be seen as a continuum, and the degree of housing affordability is a result of the relationship between the cost of housing and household income (City of Vancouver, 2011). It is not a static concept as housing costs and incomes change over time (City of Vancouver, 2011). Supportive housing on the other hand, is non-market housing, which in addition to rental subsidies, which make the housing affordable, includes on-going, targeted support services to residents (City of Vancouver, 2011). Support services include mental health and other health supports, access to resources, and links to additional community agencies (City of Vancouver, 2011). Lastly social housing/non-market housing refers to housing for low and moderateincome singles and families, falls into the category of subsidized housing as the rents vary to accommodate for different incomes. The cost of rent can range from the amount one receives as part of the shelter component coming from Income Assistance to $30 \%$ of the tenant's income (City of Vancouver, 2011). Also within the category of social housing are first stage and second stage transition homes. This type of housing is also supportive housing but specifically for women who have experienced abuse. Both first and second stages are temporary accommodation. First stage is for emergency situations and second stage is for those who cannot find a place to stay after their 30 days have passed at the first stage (BC Society of Transition Houses, 2010). This type of housing provides a temporary place of safety and support for women and their children.

\section{SigNIFICANCE OF THE STUdY}

Successful settlement in immigrant receiving nations is both a social and political challenge for immigrants in many cities across Canada. It is thus important to evaluate whether 
daily practice surrounding access to education, jobs and more particularly housing, is fair and equal (Hulchanski, 1997). The identification of barriers to successful settlement is an important area of research in the field of immigration. Existing research examining the impact of housing on the lives of immigrant populations underscores a key finding that suggests stable and adequate housing is a cornerstone, or a fundamental building block of life in a new country (Francis \& Hiebert, 2014; Murdie, 2008). In Metro Vancouver, the issue of homelessness is an increasingly visible problem however members of racialized ethnic groups are absent among the street and sheltered homeless population (Fielder et al., 2006). In contrast, “immigrants comprise a significant proportion of the regions at-risk population" (Fielder et al., 2006; p. 206). At the same time, the Metro Vancouver region "receives a disproportionate share of affluent immigrants $[\ldots]$ and this subgroup retains the largest levels of savings of immigrants" in all of Canada (Hiebert et al., 2006; p. 3). This disjuncture among immigrant populations reveals important new consequences for the participation of newcomers in the Metro Vancouver housing market. The purpose of this research is to explore the nature and extent of housing insecurity among immigrant women who have experienced IPV in Metro Vancouver. Though IPV has been viewed as a public health concern and has been extensively investigated in various fields of study, IPV among immigrant women and its connection with housing insecurity has not received much recent attention (Thurston et al., 2013).

In order to gain a better understanding of the connection between the experiences of IPV and access to housing among immigrant women, the following research questions guided the study: (1) How is the safety of immigrant women who experience IPV affected by housing concerns? (2) How does a lack of affordable housing affect the security of immigrant women leaving IPV? 


\section{LITERATURE}

This research paper includes a review of both published and grey literature including papers from academic journals, websites, and government and non-governmental reports. This ensured that multiple perspectives- including that of service providers, the non-profit sector, the governmental sector and academics are captured in the review. The search was conducted using the Ryerson University Library Archives database and Google Scholar. Combinations of the following keywords were used for the search: abuse, homeless, household, housing, immigrant, intimate partner, non-status, refugee, violence, and women/woman. Of the literature identified, 47 met the inclusion criteria (re: IPV among immigrant women and immigrants' access to housing in Canada) and were used for the literature review. Though limited, the information currently available on IPV in immigrant communities and housing access for immigrants, respectively, provides a solid groundwork for understanding these two problems together and filling the gap in terms of what remains to be researched.

\section{THEORETICAL FRAMEWORK}

This major research paper incorporates an intersectionality approach as its guiding approach in the development of this study as well as in establishing the links between this study's findings and the existing knowledge on the topics of immigration, IPV and housing, respectively. Guruge (2012) explains that "the diversity within and between groups, shared experiences within and across groups, and the intersections of multiple sites of privilege and oppression" must be considered in research and implementation in order to better understand the nature of IPV (p. 42).

An intersectionality approach entails the analysis of several intersecting sources of 
oppression at once and deems that the impact of oppression may vary depending on the combination of sources interacting with one another (Bilge \& Denis, 2010). Bilge and Denis (2010) argue that current research on gender and migration can be characterized by its consideration for the diversity that exists within the category of migrant women "and the increasing taking into account of the intersectionality of multiple axes of power relations (race, class, sexualities, age, nationality, religion, caste, able-bodiedness) shaping gendered experiences and migratory processes" (p. 3).

A framework of intersectionality operates on two levels. The first is that it works as a tool for examining structural oppression. In the second, intersectionality is used as a framework for understanding the ways that an individual's identity can shape their life. According to Kelly (2011), when this concept is applied to IPV, it requires: “(1) [an examination of] the ways in which structural inequities enable and foster IPV, and (2) examining the influence of disadvantaged social identities on women's responses to IPV, which are inherently related to the responses of helping professionals and social agencies to women experiencing IPV” (p. 44).

An intersectionality approach helps to clarify the complexity that comes with having multiple axes of social identity (such as gender, race, class, ethnicity and culture) (Guruge, 2012). This framework allows for the portrayal of the distinct ways these elements intersect and influence the stability of immigrant women who have experienced IPV and clarifies the reasons why some individuals and groups are more vulnerable to IPV than others (Guruge, 2012). A perspective of intersectionality reveals that an individual's social identities profoundly influence one's experience of gender and draws attention to the interconnections, interdependence and interlocking of these categories which may be of disadvantage (Bastia, 2014; Shields, 2008). According to Crenshaw (1991), in the context of violence against women, ignoring the merging 
and various differences of one's identity is problematic, essentially because the violence faced by many women is often shaped by other dimensions of their identities, such as race and class (Bastia, 2014). The concept of intersectionality shows the various ways that race and gender interact and shape the different dimensions of immigrant women's experiences. The many experiences that women face are not restricted to the traditional boundaries of discrimination on the basis of race and/or gender (Bastia, 2014). The intersection of race and gender factors into the lives of immigrant women in ways that will not accurately portray their lived experiences if looking at the race or gender dimensions of those experiences separately (Crenshaw, 1999).

When socio-culturally salient identifications intersect with minority/immigrant status, life circumstances and social opportunities are often negatively affected. In particular, gender must be understood in the context of power relations embedded in social identities (Rummens, 2003; Shields, 2008). According to Crenshaw (1999), "the embrace of identity politics...has been in tension with dominant conceptions of social justice" (p.1242). Crenshaw (1999) also states that in mainstream discourse identity categories such as race and gender are seen as negative frameworks within which those who are different are excluded through social power. A problem with identity politics however, is that it often conflates differences within a group and can be particularly challenging for women experiencing violence (Crenshaw, 1999). Hochreiter (2014) states that gender cannot be studied in isolation from other inequalities that exist. At the same time, these inequalities should not be studied without consideration for the historical and contextual specificity that differentiates the mechanisms creating inequality through categorical divisions.

According to Guruge and Khanlou (2004), immigrant women may define themselves as individuals through combinations of race, ethnicity, class, gender, age, language, education 
and/or immigration status. It is the intersection of these aspects that creates differences within and between groups of women. Thus, the intersectionality perspective considers shared meanings as well as changing identities and realities while encompassing the diversity within the group (Guruge, 2012). A successful approach to addressing IPV against immigrant women must acknowledge intersectionalities and the ways that multiple forms of oppression connect and shape a woman's experience of immigration, IPV, and access to housing.

\section{INTIMATE PARTNer Violence (IPV) AMONg IMMigrant WoMen in CANADA}

IPV is "the threat of, and/or actual physical, sexual, psychological, or verbal abuse by a current or former spouse or non marital partner" and can also include coercion or the deprivation of liberty in both public and private life (Tjaden \& Thoennes, 2000 noted in Guruge, 2012 p.1). IPV is common all over the world and crosses social, cultural, economic and religious boundaries. As newcomers to Canada's social services and justice system, the needs of immigrant women who have experienced IPV are particular to their experiences of migration and settlement (Bhuyan et al., 2014). According to Guruge, Tiwari and Lucea (2010), IPV is a social construct shaped by cultural, religious, socio economic and political factors. As a result, depending on the personal situation of each woman, what constitutes IPV, acceptable/ unacceptable levels of violence and how to deal with those who perpetrate the violence may be different for each woman (Vickers, 2002).

In assessing instances of IPV, studies have shown that immigrant women who have experienced IPV may face challenges also in connection to their cultural identity and loss of social support (Kaur et al., 2012; Thurston et al., 2013). They face additional barriers to escaping IPV based on norms and beliefs in their family or community. They may find it difficult to 
discuss or disclose instances of IPV due to stigma or shame, and the subsequent concern about the risk of being isolated from their families and communities (Paradis et al., 2008). The abusive partner often maintains control over the life of the immigrant woman by keeping her in the dark in regards to the various elements of their lives (ex. personal rights, immigration status, financial matters) (Braun \& Black, 2003; Kaur et al., 2012). This, along with fear of having no place to live can be used to keep the immigrant woman from leaving an unsafe situation (Braun \& Black, 2003; Thurston et al., 2013).

According to Burns (2010), women experiencing IPV will leave their partner more than once. Their return to their abuser is usually due to the inability to support themselves and their children (Burns, 2010). "The migration process can present additional challenges for immigrant women” (Thurston et al., 2006; p.9). For immigrant women experiencing IPV, housing insecurity is often cyclical and accompanied by a number of different factors (Thurston et al., 2006). Language abilities, knowledge of Canadian systems, cultural and familial backgrounds are all barriers specific to the lives of immigrants and can have great impact on an immigrant woman's ability to leave a violent situation and secure safe and affordable housing (Thurston et al., 2006). In the case where the woman has no legal status in Canada, a lack of support is often even more pronounced (Burns, 2010). The woman may fear that separation from her partner will prevent her from completing her in-country sponsorship program and may believe that she has no other choice. Morash et al. (2007) advise that although social and cultural values, religious views and different expectations of women and men are often taken into consideration, the element of migration may be overlooked in Western society. Immigration policies and social constructs can constrain and therefore shape the lives of immigrant women (Hyman et al, 2011). 
According to the Ministry of Children and Family Development (2010), often immigrant women experiencing IPV are asked why they stay in a violent situation when it puts the women and their children at risk. Women experiencing IPV often take into account increasing acts of violence, living in poverty, safety in terms of a new living environment, and the risk of leaving and losing their children in a custody battle (Ministry of Children and Family Development, 2010). Similar to these considerations, Kanagaratnam et al. (2012) have identified particular barriers that hinder an immigrant woman from leaving a violent situation and seeking help: a woman's responsibility to keep the family together, the importance of maintaining ethnic and social identity, and adherence to gender roles. A fear of deportation, belief that their existence in Canada depends on their abusive partner, fear of authority figures (usually based on past experiences in their country of origin), availability/knowledge of help services, and economic circumstances can also impact their decision to report IPV (Hyman et al., 2009; Ministry of Children and Family Development, 2010). In their research, Hyman and colleagues (2009) found that in the instances where women did report IPV, it was more commonly disclosed to informal sources of support while smaller proportions of immigrant women reported their experiences of IPV to the police or social services.

The interacting factors affecting each woman's experience of IPV can be found at the individual, family, community, and societal levels (Guruge, 2012). At the individual level, marital status, age difference between partners, mental health status, and alcohol or drug use/misuse can impact IPV (Guruge, 2012). A history of childhood abuse can also strain a couple's relationship and can be a contributing factor. At the family level, the migration process often demands for a change in family structure and dynamic, thus aggravating acts of violenceespecially "if these changes challenge traditional gender norms", giving more power and time to 
the woman (Guruge, 2012; p. 40). At the community/ societal levels, a range of factors, including political conflict and instability, "rigid gender roles, a sense of male entitlement, authority and ownership of women; religious approval and chastisement of women; and a cultural ethos that condones violence as a means of settling interpersonal disputes can lead to new and aggravated episodes of IPV" (Guruge, 2012; p. 40). However, Worden and Carlson (2005) as well as Berkel et al. (2005) have found through surveys with members of the Canadian public that IPV is mostly thought of on a personal level only considering the individual, the relationship or the household. I.e. society and culture were not viewed as root causes.

\section{Housing Situation in Canada}

Existing research examining the impact of housing on the lives of immigrant populations underscores a key finding that stable and adequate housing is a cornerstone, or a fundamental building block of life in a new country (Francis \& Hiebert, 2014; Murdie, 2008). Although no family of any kind is immune to housing crises, some families experience the precariousness of housing arrangements more intensely than others (Francis \& Hiebert, 2014; Hulchanski, 2005; Paradis et al., 2008). According to Francis and Hiebert (2014), housing can be seen in terms of a continuum with security at one end of the spectrum and insecurity at the other end. Six main factors most strongly affect where an immigrant family may land on this continuum: socioeconomic factors; employment; role of service providers and advocates; health impacts; personal safety issues; and the influence of gender and culture on housing (Francis \& Hiebert, 2014; Paradis et al., 2008; Thurston et al., 2013). Being on the secure end of the spectrum would include stable housing, allowing newcomers to meet both personal and family needs. Housing stability has also been a factor that can aid with pursuit of education, finding and maintaining 
employment, recovering from trauma and contributing to their communities (Francis \& Hiebert, 2014; Miraftab, 2000; Wachsmuth, 2008). A lack of stable housing, on the other hand, is linked with higher rates of unemployment, increased stress, and a longer and more challenging process of integration, putting the structure of settlement at risk (Francis \& Hiebert, 2014; Francis, 2008; Gillard, 2014).

When a country as wealthy as Canada is unable to properly and adequately house its population, there is a housing affordability problem (Hulchanski, 2005). According to the Federation of Canadian Municipalities (2011), Canada is one of the few Western nations that is almost fully reliant on market mechanisms for supplying, allocating and maintaining housing stock. As a result, while the "market demand for housing is addressed; the social need for housing is not" (Hulchanski, 2005; p. 1).

In terms of housing, when studies refer to immigrants who are dealing with housing insecurity as the 'hidden' homeless or as those in 'vulnerable households', it is due to the fact that they may be living in illegal or temporary accommodation (Fielder et al., 2006; Hieber et al., 2006). Many immigrants are at imminent risk of becoming homeless but the difficulties they face in the housing market are essentially invisible (Fielder et al., 2006; Hiebert et al., 2006; Kaur et al., 2012). Living in a house that requires major repairs, that is too small or costs $30 \%$ or more of a family's total income would qualify as being in 'core housing need' (Fielder et al., 2006). Immigrant families in Canada are nearly 1.5 times more likely to fall into this category with approximately 20 percent of immigrant households already in core housing need (Carter, 2005; Hiebert et al., 2006; Hill, 2011). Although academicians and policy makers are aware of the vital role of housing in relation to the economic and social outcomes of new immigrants, there is comparatively little substantive discussion on strategies to devise housing policy as part of 
immigrant settlement and in response to the distinct needs of this population (Wachsmuth, 2008).

\section{IMMIGRANT WOMEN, IPV, \& HOUSING}

Thurston et al., (2013) are the only researchers in Canada who have explored, through an extensive study, immigrant women's pathways into and out of homelessness in relation to family violence and have found that the issue of housing insecurity is not only an obstacle for immigrant families but also a major barrier for immigrant women leaving a relationship where they experience IPV. Housing insecurity may force any abused woman to live in substandard conditions or to return to her abuser but for immigrant women facing barriers related to ethnicity, status and culture instability in regards to housing is an additional impediment to settlement. Immigrant women, especially those with precarious status, are extremely vulnerable, often living in conditions of poverty, housing instability, danger and exploitation (Paradis et al., 2008). The few Canadian studies that have explored the link between IPV and housing insecurity have found that the most common reason that immigrant women have left their last stable place of living was due to IPV (Paradis et al., 2008; Thurston et al., 2013). Other reasons for leaving included bad housing conditions and issues related to affordability (Kaur et al., 2012; Thurston et al., 2013). Some immigrant women's reasons for leaving are related to the particular difficulties of women who are pregnant or caring for children in finding and keeping housing (Paradis et al., 2008). While family shelters were initially intended as a resource for situations of crisis, many across Canada are functioning as transitional and supportive housing for immigrant women who have experienced IPV, supporting the women and their children (Kaur et al., 2012; Paradis et al., 2008). Paradis and colleagues (2008) have found that access to transitional and supportive housing allows for a more home-like environment within which the women and their children 
can stabilize their lives with appropriate services available, rather than having to live in overcrowded conditions in shelters with people whose situations differ greatly from their own.

The need for alternative housing is all the more pronounced for immigrant women who may not have any established support systems that could provide temporary accommodation (Thurston et al., 2013). Thurston et al. (2013) concluded that a woman's immigration status could affect her ability to seek and obtain government income assistance, delaying any attempts to leave an abusive situation, and contributing to further economic dependence on the abuser. Bhuyan et al. (2014) have found that women who have experienced IPV often face difficulty in accessing shelter, income, and legal assistance. Lacking any of these elements can be the difference between returning to the violent relationship and finding independence after having a volatile situation.

The majority of immigrants moving to Canada relocate to Toronto, Vancouver or Montreal, the three largest metropolitan centers of the country (Carter, 2005). Sixty two percent of the foreign born population of Canada and 73 percent of recent arrivals (since 1990) move to these three regions, confirming the need for their consideration in terms of housing within these centers (Carter, 2005). Thurston et al. (2006) conducted a multi-site study in Calgary, Winnipeg, and Halifax. Though Thurston et al. (2006) have explored the causes of persistent and repetitive homelessness among immigrant women experiencing family violence; their study is one of the only comprehensive analyses of immigrant women's experiences of violence in connection with homelessness and is not specific to violence caused by an intimate partner. Although many studies confirming that the Metro Vancouver housing market is amongst the most expensive and difficult to access in all of Canada, many individuals, not only immigrant women, have difficulty securing adequate housing in the Metro Vancouver area (Francis, 2010; Francis \& Hiebert, 2014; 
Fielder, Schuurman \& Hyndman, 2006). Thus, immigrant women's experiences of IPV in Metro Vancouver in terms of accessing housing require urgent research attention. This study aims to address this knowledge gap by exploring the initial housing options available to immigrant women when attempting to leave a situation of IPV and identify the barriers they face as a result of their legal status in Canada.

\section{CHAPTER 2- METHODOLOGY \& DESIGN}

\section{RESEARCH DESIGN}

A qualitative interpretive descriptive design is used as it allows for the advancement of knowledge based on the experiences of individuals (Thorne, Reimer-Kirkham, \& O'FlynnMagee, 2004). Interpretive description recognizes both the constructed and contextual nature of the human experience, which allows for shared realities (Thorne, Reimer-Kirkham, \& O'FlynnMagee, 2004). This method complements the intersectionality approach used as a framework for this research, focusing on the diversity within immigrant women along with the contextual factors that create diverse forms of oppression.

\section{STUdy PaRTicipants}

In order to recruit immigrant women participants, the assistance of service providers at three different immigrant-serving organizations in the Metro Vancouver region was sought. 'Purposive sampling' was employed to allow for a series of strategic choices regarding who would be interviewed, where the interviews would take place and how to do the research, taking into consideration the specific inclusion criteria (Creswell, 2007). The inclusion criteria were: immigrant women and service providers who had experience working with immigrant women 
from a number of different countries who have dealt with IPV and have had difficulty accessing housing in Metro Vancouver. In addition, 'snowball sampling' was used with the help of women and service providers who had volunteered to participate to find other contacts. Snowball sampling allowed for the identification of participants who were interested, through people who know others who are also in this situation and are information-rich (Creswell, 2007). Initial participants, both immigrant women and service providers, made helpful referrals for other potential participants they felt would be interested in taking part in the study. In depth interviews were conducted with immigrant women who speak English and are above the age of 18, who had experienced IPV and difficulty in the housing market regardless of their immigration status in Canada. In addition, service providers from immigrant serving agencies were interviewed in English to get their points of view on the issues facing immigrant women who have experienced IPV.

\section{RECRUITMENT}

Once ethics approval was obtained from the Ryerson Research Ethics Board, my involvement as a practicum student as part of my placement position for my masters degree allowed me to become familiar with a number of individuals and organizations working with the study population that I had selected for this research. After obtaining permission from these agencies, I was able to recruit participants through these connections. Some participants were informed of the possibility of their participation through in-person conversations while others were contacted by phone or email using a prepared script, which included general information about the study. Potential participants were asked if they would like to volunteer for a face-toface interview, with knowledge of the time commitment and that their identity and the 
information shared would remain confidential. Interviews were conducted by myself and arranged at a time and place that was suited for the participants.

\section{ETHICAL CONSIDERATIONS}

Before the interview began, every potential participant was informed both verbally and through the informed consent form, the sensitive nature of the questions, of their rights to refuse participation, refuse to answer any questions or to stop their interview at any given time. The informed consent form gave details of who was conducting this study, the purpose of the study, what participation entails, the nature of voluntary participation, the right to withdrawal at any time without giving reasons or affecting their future care/services, rights to confidentiality of information shared, and right to refrain from answering any questions. The participants were able to reconsider their participation within the first month of being interviewed, should this have been their decision, the interview notes would have been completely destroyed. This was also indicated on the informed consent form and explained to participants at the beginning of the interview. A small amount of $\$ 30$ was provided to the participants to cover the costs of childcare, transportation, and time for taking part in the interview.

\section{Data Collection}

In total, 15 interviews were conducted; each in a private room at an immigrant serving agency that is easily accessible to the participants in order to ensure their comfort and safety when disclosing information. Conducting interviews in such settings allowed the women access to counselling and/or emotional support services at the agency in the case where they needed such support. The semi-structured, qualitative interviews took approximately 1 hour each. The 
first 10 to 15 minutes of each interview was dedicated to ensuring that the participants were aware of the purpose of the study, study benefits, risks and risk management, confidentiality and the voluntary nature of their participation. Consent to audio-record the interviews was obtained from each participant and each individual was informed that only I, as the primary researcher, would listen to the audio-recordings in order to transcribe each interview. The audio-recordings were saved in password-protected files and then deleted after the transcription process was completed.

\section{Data Analysis TechniQue}

The first stage of data analysis included the preparation and organization of the data collected. This includes the audio recordings, which were transcribed, along with the notes taken throughout the interviews (Creswell, 2007). Data analysis was based on inductive thematic analysis (Bryman, 2001). This method allows for the examination and recording of patterns within the data through an open lens, to allow for contrasts and comparisons and allows the themes that are important to participants to emerge (Bryman, 2001; Guruge, 2012).

The codes were thus organized into categories of analysis. To make sure to break down these steps and ensure clarity, the data analysis spiral represented in Creswell (2007) was used. Transcripts were read and re-read several times to get a better sense of each interview. Memos (in the form of short phrases or key ideas) were written in the margins and compared and contrasted with the transcriptions. This was done through a process of coding and condensing the data. Data coding was done manually and analyzed based on the intersectionality framework. My MRP supervisor also reviewed the coding. Once the coding scheme was developed, the remaining interviews were coded using a process of going back and forth between reading and 
making notes and then moving toward describing, classifying, and interpreting the data to highlight the major themes arising from the fifteen interviews and to identify commonalities and differences among the responses and stories. The findings highlight the extent to which Canadian policies and practices surrounding immigration, violence, and housing affect immigrant women experiencing IPV.

\section{CHAPTER 3- FINDINGS}

The findings drawn from the analysis of data are presented in the following section. Selected vignettes from the interviews have been presented, using the words of the participants. The findings suggest that the various aspects of an immigrant woman's identity that are tied to the settlement challenges in a new country and the additional impact of IPV are strong factors that lead to women's housing insecurity.

\section{INTIMATE PARTNER ViOLENCE \& IMMigRATION}

\section{Perceptions \& Experiences of IPV}

The violence reported in the interviews varied greatly; with some participants who had experienced verbal abuse less frequently, to others who had lived through years of severe physical and psychological/emotional violence. Women had experienced varying levels of physical violence (i.e. hitting, punching, choking, throwing of objects), sexual violence (i.e. sexual control/assault), verbal abuse (i.e. swearing, yelling), psychological/emotional abuse (i.e. manipulation, threats, harassment), social abuse (i.e. social isolation/control of contact), and financial abuse (i.e. perpetrator retains all control of finances). Some women also experienced all of the above during pregnancy. Women and service providers explained that many were unaware 
or did not acknowledge their experiences as IPV until a friend or someone assisting them at an immigrant-serving agency told them so.

The majority of participants explained that back home IPV had persisted for generations and because it is so common, they are often not aware that they should report it. A multicultural support worker talked about the perceptions that clients have of violence, explaining that "it could be financial, emotional, verbal but unfortunately, $90 \%$ of my clients don't even know that verbal and emotional are both types of violence... because he's not hitting, because there's no bruises then that's okay. Whereas they don't know that emotional abuse can have detrimental effects and leave scars on the heart."

Women generally refrained from speculating as to why the violence started although some of the findings indicate that a shift in family dynamics, immigration status, and loss of control (abuser's control) played a role in some cases. For the women who came from different cultural backgrounds than their abusers, the partners were often Canadian or had been in Canada long enough to assert their control through their knowledge of existing systems and their advantage in terms of language and immigration status. Acts of IPV can have a range of intensity. The following are accounts highlighting instances of IPV in different forms (emotional, financial and physical):

"He used to lock the doors from the inside and would leave from the garage so that I would not be able to get in with my keys and what I used to do is just stay in the backyard until the middle of the night when he was back... hot, rain, it didn't matter the weather. It was constant emotional abuse” (Participant, Non-Status, Turkmenistan).

"My ex was constantly showing me that everything was a success for him because he was the one who was able to bring me here to Canada. He kept telling me to think of how helpless I 
am since I was not working and was financially dependent on him. Even then, I didn't have access to any credit cards or passports or my kid's birth certificates, not even my own PR card" (Participant, recent Canadian Citizen, Pakistan). This woman experienced economic subordination resulting in emotional abuse, likely motivated by a need for control.

"He hit me in the arm and my phone fell and in one second he punched me. My son was sleeping right there in the middle of us and then I stood up and went around the bed and he punched me again and he grabbed a bottle and he started hitting me with that and my hands were all bruised and my son woke up of course from the noise of my ex's yelling so I left the room and my son was just so scared and my ex was following me and my nose was bleeding..." (Participant, Non-Status, Mexico). This woman explained that she experienced this type of physical abuse after her partner saw that she was texting to arrange plans with her brothers. By creating a climate of fear, the partner was able to reinforce his control to ensure that she would listen to him rather than members of her family.

That which was the least tolerable for the women was the type of control that their partners could exercise over their children. One woman explains: "I had no position in the house and another thing that I could not handle was that he was working on brainwashing my child against me" (Participant, Permanent Resident, Iran).

For some women, violence was already part of their intimate relationships prior to coming to Canada while other women first experienced violence after arriving to Canada. In both cases, immigrant women were unaware of the fact that within Canadian society, IPV is defined to include social, psychological, spiritual and financial abuse, and has established a wide array of services to aid both victims and perpetrators- most of which can provide help regardless of the victim's immigration status. Thus, the ways in which the participants understood their 
experiences of IPV and what they can do about it were dependent on their social and cultural reality.

\section{Influence of Gender \& Culture}

Gender and culture shape immigrant women's experience of IPV and access to housing but it is the intersection of these identities that presents greater impact. Considering the multiple boundaries crossed by immigrant women- ethnic, racial, class, gender- it is important to analyze the ways in which different forms of disadvantage intersect and illustrate the experiences of certain groups of women on the basis of these aspects, simultaneously.

When describing inequalities based on gender, a service provider stated: "when we talk about IPV it is violence against women...the overwhelming perpetrator are men and it comes from our society; we have a systemic belief system which places women in the house, men out earning and even though we say no we are equal now, women are still overwhelmingly in charge of caregiving, women are still earning 82 cents to a man's dollar and then they're going you know well, that's choices...but if life is a buffet then women are lactose intolerant, you know?" (Participant, Service Provider, Legal Advocate). The metaphor was used to explain that our society is not structured in a way to allow women the same full choices that are available to men, and that each marginalized group is affected in their own way. In other words, a woman, who is an immigrant and maybe does not have status, has experienced IPV and is looking for housing would get salad in life's buffet.

Many of the women who participated as well as the service providers agreed that it is common for immigrant women experiencing IPV to feel that they are alone. Many expressed that they were unaware that women from other countries and cultures also experienced IPV. It was 
not until accessing formal help that these women realized that they as individuals, and the cultures that they come from, are not unique to that IPV. A support worker at a transition house explained regarding her many immigrant clients: "the violence and abuse that they experience is historical so when we talk about the women's mothers and grandmothers and aunts and the mother in law, the sister in law, they all have the same issues...so nobody has been able to support them, you know, they always say well this is it, this is marriage and this is the role of women in the family." Often demeaned by their current abusive partner, families, teachers, and by their governments, immigrant women experiencing IPV lack the motivation and courage to come forward. Years of oppression surrounding gender and culture forced them to justify the struggles that they face. Especially when these experiences also take place during their process of immigration, it is common for women to feel that they must protect the image of their family and culture thus preventing them from revealing their experiences of violence. However, understanding that no matter where a woman is from, the violence can occur, helps to relieve some of that shame.

\section{Influence of Immigration Experience}

While some participants immigrated with their partners, others met their partners in Canada after having been in the country on student or visitor's visas, and later, permanently immigrated in order to continue their relationships and most were hoping to get sponsored. For those in the latter situation, first experiences in Canada were positive. As one participant recounts: “... when I came, I did not plan to stay so everything was very nice from my point of view. I was travelling and saw so many things in that time...it was almost like a vacation" (Participant, Permanent Resident, Romania). 
Similarly, a woman without legal immigration status, originally from Mexico explains: "every year has been different like when I first came to Canada, I was single, it was okay and then I worked and I don 't know...I didn't have any expectations, I was just living day by day and I was really young, I mean I was only 17 so it was more like, oh yeah, I'm getting married and all that stuff. I was just living in that bubble." Similar to the case of this participant, the women who were hoping to be sponsored by their partners often got carried away with Canadian life, trusting that the men would take care of matters relating to immigration.

Over time, however, the life described above changed when combined with the various barriers each woman would face. According to participants, when one starts a life in a new country, relationships with intimate partners become more difficult and arguments arise. Often such arguments would stem from conversations surrounding sponsorship- a burden that the spouse or partner was able to hold over the woman. Many of the participants were under the impression that their partner would sponsor them, however, they were often presented with excuses and were left without status. The following are quotes from some participants who had difficulty getting their partners to follow through with their promise to sponsor: "I got married to him and he had promised me that he would sponsor me...even though things were not going well I thought I should stay with him and maybe he will fulfill his promise too but then I saw that it was not going to happen" (Participant, Non-Status, Mexico). Often, immigration status may act as a barrier to women leaving a situation where they are experiencing IPV. When the only way of remaining in Canada is to hope that the partner will follow through with his commitment and sponsor the woman, many will put up nearly anything.

Another participant shared her experience: "so basically he asked me to do all the paper work and he would just sign but I was a new immigrant to Canada, right...and especially 
government paperwork was difficult and took me so long to just do the paper work. After a lot of back and forth about it, this time he was really willing to help me with immigration but after I went back to Japan he start saying he doesn't want to do it because he feels like I only wanted immigration and sponsorship from him but I told him that's not only reason I married him but he didn't believe me" (Participant, Permanent Resident, Japan). Immigration related barriers were evidently prominent in this woman's relationship with her husband. More specifically, language was a significant barrier that allowed her husband full control over the element of immigration, which eventually lead to control over all elements of the woman's life. The mere notion of having the ability to fill out an immigration application when the woman cannot subordinates the woman to the man.

After several years of staying in their relationships, participants were still unable to have their sponsorship completed by their partners. Once separated, the only option participants were left with was to apply to stay in Canada on humanitarian and compassionate $(\mathrm{H} \& \mathrm{C})$ grounds as they would not be able to return to their countries of origin with their children. Completing this application is a long and difficult process, which can take several years. Another Japanese participant described her experience as follows: "For the $H \& C$ application, I went to legal aid with my care worker and they helped me get legal aid and I got a lawyer. So I applied for this application in 2010 right after the separation happened but I got denied for it a year later just because at that time I was 7 or 8 months pregnant but the immigration officer said you are by yourself so you can go back to Japan but like my baby was going to be born just a month or two later, I was not able to travel...so my lawyer said that didn't make sense and I re-applied and then I got the permanent residency $(P R)$ in December 2014 so I struggled for 4 years to get the PR...it killed $m e "$ (Participant, Non-Status, Japan). The H\&C application in itself presents a 
difficult process, adding instability to the woman's life and creating yet another element by which she can be marginalized and oppressed by others.

Some participants stayed in violent living situations in order, to at least, secure their immigration status. As noted above, this was unsuccessful for most and led to precarious status until their applications were accepted some years later. During this time difficulties persisted in all areas of their life as everything was tied to their (legal) status in Canada. Lack of immigration status removes all possibility for housing subsidies as well as childcare subsidies- rendering it even more difficult for women to escape IPV and to find a place of their own.

Immigrant women, particularly those being sponsored or those under the impression that they were going to be sponsored were regularly misinformed of their rights in Canada. The majority of abusive partners were familiar with the Canadian systems and were therefore able to manipulate the women. Another participant explained of the time in between the renewal of her visitor's visa: "He kept telling me he was going to have me deported if I didn't listen to him, so, of course, I had fear of deportation but really I had done nothing wrong, he just had so much control that I couldn't see this for myself', (Participant, Non-Status, Turkmenistan). This lack of knowledge surrounding individual rights and immigration laws was observed by all of the service providers interviewed as they described the necessity for new immigrants to be made aware of their rights in Canada from the outset of their immigration process.

\section{Leaving an Abusive Partner}

As confirmed by service providers and immigrant women, the period of IPV was often long and accompanied by several unsuccessful attempts to leave. It was common for women to leave an abusive partner often for a few days or a week but threats from the partner or his 
promise to change, fear of bringing shame to the family or cultural community, lack of financial means, and the desire for stable and adequate housing would often send women back to the relationship. These events can be characterized as part of the cycle of abuse explained by one of the service providers, a counselor, who was interviewed: "sometimes when women come, they are kind of calm, they are happy, they say we were fighting a lot last month but now everything is okay... when we ask more questions we realize that fundamentally, nothing has changed so we realize that this is like a honeymoon phase and we ask, does this happen a lot? That you guys start having arguments and then it escalates and then it erupts and after that you may be separated for a week or so... but because of different financial needs or because of the children, you get together and he shows remorse? And usually that is the case so we call this the cycle of abuse and it is usually an eye opening conversation that we have, they say oh yeah...it happens at least 4 times a year" (Participant, Service Provider, Counselor).

In most cases, participants disclosed their experience of IPV through services that they were receiving for settlement, rather than through violence focused agencies. Some were assisted by the staff at immigrant serving organizations, counselors, ESL teachers or by individuals working at their children's schools. It was not until their trust was gained that these women shared these extremely personal experiences. In cases where the violence was extreme, the women themselves or someone close to them called the police. The police escorted the majority of participants to emergency shelters or first stage transition homes. For other participants, making the decision to leave was prompted by the awareness of available resources and supports.

There are many different interconnections within an immigrant woman's experiences and these are magnified for women who have experienced IPV by a man who is also part of their cultural group. They are often concerned about whether the disclosure of this information will be 
a reflection of their culture. This train of thought is a very foundational way of thinking for most participants. One participant stated: "So I came from a culture where your marriage is your first ever relationship with a male, right? So I had no idea how this thing works. All I knew is like...I'm new in the country, the only family I have are his parents and him, that's all I have, so I'm not going lose it so I just did whatever they wanted me to do...so it's like you're just constantly trying to transform yourself to be someone else...somebody whom you don't want to be... to accommodate them. That's all your life is from day to night that's all you do and then I became a mum at quite a young age and it's just even bigger responsibilities but then it just gets worst and worst when as humans we all have our limits...you eventually realize you can't live your life like a puppet." (Participant, Canadian Citizen, Pakistan) Similar to this statement, for some women, the biggest barrier to leaving was the sense of guilt, especially when belonging to a culture where women are conditioned in a way to accept things for the way they are and to just find a way to cope and survive.

The women participants expressed that money and a place to live were both huge concerns for them before making the final decision to leave. Several women explained that if they had been alone it would have been easier to leave or to live on the street but being with children required stability and safety. With the abusive partner's family being their only network in Canada, every other option for a place to live when leaving the home of the abuser was temporary. A woman interviewed recounted her reasons for staying as long as she did: "I really didn't have a better option. The living conditions with my ex who was smoking weed were so bad but working at Subway really didn't make me much money and I knew I wouldn't be able to support my son and myself so unfortunately it was the most convenient option... but I was really unhappy and used to cry every night until I left" (Participant, Permanent Resident, Japan). 
A woman's decision to leave permanently was most often motivated by the intensification of violence where the safety of children was at risk. When the living situation with the abusive partner escalated to a point where the environment was affecting their children both emotionally and psychologically, women realized that they had to make a change.

The decision to leave was a difficult choice to make: "At the beginning when we first got to Canada it was such a hard time for me and I really felt like the world had ended for me, I thought that I could not continue to live here until the time that he suggested himself that we should get back to each other. Now that I am separated from my husband, I see that those efforts and struggles that I was making to have a life with him had no point...um...they were for no reason and would not have come to the results that I want in a life "(Participant, Permanent Resident, Iran). After permanent separation however, women often realized their full potential and strength and were able to envision a life without the violent partner.

\section{THE QUEST FOR HOUSING}

\section{Affordable Housing}

Finding safe and affordable housing proves to be a greater challenge for immigrants who do not belong to the economic or business class than it is for the women who were part of these groups or for native-born Canadians. Lack of access to adequate housing can slow the process of successful integration of immigrants into their new communities. The barriers with which many immigrant households are faced with respect to housing are associated to affordability, with low incomes in relation to high rents, long waitlists for social housing and a lack of resources to accommodate larger families and the socio cultural problems that they may experience. Before actually leaving situations of IPV, women often safety plan by assessing the barriers they are 
facing. As stated by one of the service providers interviewed, "women are born safety planning... and when you're leaving abuse, you're still safety planning so it's a question of how do I make sure that I've got my rent or food on the table? The other thing is, especially when children are involved that it's going to be a fight. How do I make sure that I can have my kids with me? So they have to have housing and it has to be good housing in order to feel secure to leave and this is the thing too... it's that when women are forced to go back to ex-partners because the system is not there, it's much worse for them. So women really have to get it right, so if they don't see that they can get into housing, it does create a huge huge barrier for them. Even just the perception of not being able to get into housing..." (Participant, Service Provider, Legal Advocate).

For participants, their security and safety as well as that of their children was the most important factor to finding housing. The women's financial situations as well as the availability of subsidized housing not only determined but also jeopardized the stability of their housing options. The above is portrayed by one woman's account: "Money was the biggest and place to live both were huge because I was with my son like if I was alone, I could do something else, I could sleep on the street it would be okay but with my son, I don't know what I could do. My biggest concern was my son, emotionally and the environment's effects on him psychologically" (Participant, Permanent Resident, Korea).

For the majority of participants, affordability was an issue, and as such, they were always looking for something cheaper and were, thus, constantly on the move. Some were going from place to place in order to find something more affordable while others were re-adjusting after having had to live with other families or roommates. These aspects surrounding the search for housing in addition to other elements such as IPV or job insecurity created a huge domino effect 
that negatively affected the women's ability to settle in this new country. This was rendered even more difficult due to the fact that most women participants had no family to rely on while things settled out.

While access to subsidized housing did provide a sense of calm for most women, BC Housing lists are long and cannot guarantee a place to live. One service provider explained: "We always help them register for BC Housing but that is normally a two year wait so for more volatile situations, it is not an option" (Participant, Service Provider, Multicultural Worker). In addition to long waitlists, many units that the women had visited were in bad conditions; with bad smells and dirty carpets, and in unsafe neighborhoods. One woman acknowledged that although she was not in a position where she could be picky, she still did not choose a lot of the options available to her simply due to poor upkeep and less desirable conditions. Another participant explained of her current living condition in a subsidized suite through BC Housing: "My husband picked this place I live in without telling me and he took the BC Housing list and hid it from me. I also did not speak very good English and I cannot read so everything he told me was not true and I didn't know. There is a lot of damage in the house that was there from the beginning, the cupboard even fell on my face and injured me and I told the manager but he says that it was not like that before and it is my fault. Now, I have to pay money that I do not have to fix it. It is not safe for me and especially not for my little kids" (Participant, Permanent Resident, Sudan).

As stated earlier, income was a huge barrier to housing security for the participants. The majority of women were dependent on some type of income support, most often income assistance from the government. Although the latter did allow for the women some independence, the income was low and not adequate to support housing and other basic needs. 
For the women who did not have legal status and were not eligible for income assistance, the rental market was their only option. One woman described the way she has been living: "The suite that I live is very small but very cheap and at least we have privacy. My situation was different than everybody else because I was not on welfare. Most people usually have welfare and can get approved by BC Housing and move into subsidized housing places but I had no way to get into them even. So I was getting $\$ 580$ from spousal support and I needed a phone so I paid $\$ 30$ for the phone and only had $\$ 100$ every month for living for the last 3 years...I don't even know how I did it. I am trying to forget it now" (Participant, Mother without status, Japan).

In many cases, lack of information, regarding where to receive help or how to find accommodation, led the women participants to spend several nights at the airport, shelters or the homes of friends or acquaintances. The lack of support and information was also intensified by gendered cultural circumstances such as leaving abusive situations, facing shame and stigma, living on their own, and becoming the head of the family for the first time. Participants indicated that a key need upon arrival to Canada was access to information on a number of topics including services related to housing options, particularly for women in emergency situations.

In an interview with one service provider, the concept of a false choice was introduced in regards to housing. According to this individual, a city counselor had stated that affordable housing in Vancouver means that somebody can afford it, therefore meaning that different people prioritize different things. This however is a false choice and a problematic way of thinking. While everyone prioritizes having a roof over their head, it does not mean that everyone can afford to spend three quarters of their income on housing. The service provider further explained, "this is what these Housing First models are showing, that if you have housing, you can fix other problems, but if we say you don't get housing until you fix the other 
problems in your life then people don't fix these problems, you know? So in a way, we are setting people up so that that way they lose their housing..." (Participant, Service Provider, Legal Advocate).

\section{Transition Homes}

While some of the women were living in transition homes at the time of the interviews, a few explained that prior to the emergency situation which led them to emergency shelters or first stage transition homes, they were unaware of the existence of such types of supportive housing. Others spoke of their worries in regards to transition homes both based on their own assumptions and misconceptions but also in regards to comments they received from friends and acquaintances. One woman described her preconceived notion regarding transition homes: "I thought there would be people there because of alcohol abuse, smoking, drugs...but when I went it was families, like in the same situation as me." (Participant, Non-Status, Mexico)

This negative image of what it would be like to live in a transition home was common among participants and was further reinforced by the discrimination expressed by others. Participants felt that they were being judged and as one woman explained, it hurt her but at the same time she knew that she was lucky to be there and that she had to heal herself so that there would be no violence or abuse in her future and that of her son.

Another participant also describes her reaction to the transition home: "I applied to second stage and I never had lived in Surrey and I had heard of the reputation here so I was a bit concerned but when I came for my interview, it was a really good surprise. It was really a clean and beautiful building, I had a negative image in my mind but it was totally opposite, 
everything was provided, it was fully furnished even utensils, pots and pans, toilet paper and everything." (Participant, Canadian Citizen, Pakistan)

Although those participants living in transition homes were grateful to be there and appreciative of the help from the staff, they were all aware that the nature of this type of housing was temporary. As a result, most were looking for affordable housing in order to move out before their time at the transition home was complete. Long waiting lists for subsidized housing jeopardized the feeling of safety that the women had just recently regained when settling into the transition homes. That being said, it was stated by one service provider that it is much harder for those who have not stayed in transition homes to gain quick access to subsidized housing. She explained that with her outreach clients, trying to get them into affordable housing was extremely difficult but for those who had lived in the transition home she was able to support their applications and confirm the type of tenant they were as their landlord and reference. Unfortunately, those women who did not have anyone directly responsible for their files had more difficulty finding secure housing.

\section{Role of Service Providers}

Four service providers, all working in different roles, were interviewed in order to gain a better understanding of the issues facing their clients. As individuals working within the field of social services for immigrants, all four experienced similar difficulties in their quest to assisting clients. With barriers related to a lack of funding or resources, a common sentiment expressed was that although they were helping, they felt that they were actually unable to help due to systemic barriers. On the contrary however, the majority of women interviewed recognized that finding housing was only possible for them through the advocacy and persistence of service 
providers from transition homes or immigrant serving agencies. It was only with the aid of service providers that the immigrant women interviewed were able to secure space in subsidized housing. Those interviewed who did not spend any time at a transition home and were not in contact with support workers had extreme difficulty even filling out the application to get onto a waiting list. The service providers themselves agreed that the application process in itself is barrier even for English speaking Canadian-born, educated women. This type of assistance in itself relieved a lot of stress that the women were experiencing, as the application is lengthy and does not even guarantee a place to live.

The service providers help with a wide array of needs; from accompanying women to appointments or court hearings to writing letters of support for the provision of housing or income assistance/childcare subsidies due to changes in family structure. While long wait times are common for any type subsidized housing through BC Housing, it was through the support of service providers that women were placed on priority lists on account of the IPV that they would be exposed to otherwise. Their well-established networks both within and outside of their own areas of expertise were extremely helpful in assisting women to secure housing.

In many cases, the women were mothers who did not have legal status in Canada and therefore faced a series of hurdles barring them from access to subsidized housing. One participant explained: "I stayed in the first stage transition home for 30 days so my time was up but with the help of my case worker for violence and abuse, they were able to extend my stay until they helped me find a more permanent place to live" (Participant, Non-Status, Turkmenistan).

A service provider working at a transition home explained that "[they] work really hard to get the mothers without status into permanent housing. [They] have relationships with other 
housing providers to be able to take the women if they are on income assistance. That seems to be the big one, to make sure that they are on income assistance. Often just receiving child support seems to be sticky for a lot of place so [they] work hard to build strong enough relationships that [they] can vouch for these women." Further emphasizing the support worker's role in helping women find housing, a participant who had just settled into permanent subsidized housing stated: "The support worker was a big help because of course this is BC Housing, right? So supposed to have a steady income to get in here but I had no status but the worker said she could help me get income assistance for hardship and once I get that then I could have a steady income and become a resident here. So she helped me find a way to get in without status and the reason why I was approved was that they pushed income assistance even when my $H \& C$ application was still being processed. They explained that in a case like mine most people were approved as permanent residences so since I will be a PR in the future, it's just a matter of time even though I have no status right now. So they pushed income assistance to give me money for hardship and I was able to find housing" (Participant, Non-Status, Japan).

Along with supporting women through the trauma of IPV, aiding them in their search for housing and assisting them with income and other subsidies, all service providers emphasized the need for the empowerment of their clients and saw themselves as their advocates. This was shown through their common mission of empowering women to be independent and to lead lives free of violence and abuse. As one participant put it, "[their] clients know of course that [they] don't endorse or recommend, because [they] want to emotionally support women to make their own decisions" (Participant, Service Provider, Counselor). In other words, service providers support women in whatever choices they decide to make and are there to make sure that their clients are well connected with any resources that could be of assistance to them. 


\section{CHAPTER 4- CONCLUSION}

\section{DISCUSSION}

With a growing immigrant population and rising costs of housing, planners are faced with the task of accommodating an increasingly diverse population in Canadian cities. As Carter (2005) has stated, "planners are faced with the challenge of accommodating a growing number of visible minorities who often face racism and discrimination in the housing market. The challenge is to accommodate 'the world' in a city"- a challenge which can have evident impact on immigrant women who have experienced IPV (p. 284).

All of the participants interviewed in this study were, or currently are, experiencing critical housing stress. While this can be said for all groups in the Metro Vancouver region, participants face challenges symptomatic of their immigration class and in connection with experiences of IPV. Uncertain immigration status, lack of language abilities, an absence of social networks and a very limited amount of affordable housing indicates immigrants' exposure to precarious housing situations, an outcome that has implications for their future integration into Canadian society. More particularly, for women awaiting immigration approval, these smaller barriers intersect with larger structural barriers that prevent them from full participation in Canadian society.

So long as housing is viewed in our society as a commodity rather than a right, it is women and children who will experience the detrimental effects. Women, specifically those belonging to immigrant or visible minority groups, are more likely to be disadvantaged in terms of resources needed for survival. While IPV may drive women to leave the home, social policy dictates the level of housing actually available to them whether it is temporary or permanent. Immigrants within the at-risk population are often unable to find housing that is both secure and 
affordable. This scarce supply of affordable housing results in "high rent-to-income ratios among the least well off and puts them at-risk for economically-induced homelessness" (Fielder et al., 2006; p. 208).

Often, immigrant women face systemic barriers or unique challenges to accessing housing in connection to their immigration status. Difficulty with the English language, unfamiliarity with the Canadian systems, cultural background and family structure all contribute to the immigrant woman's experience of leaving a situation of IPV and securing adequate housing for herself and her children. Their lack of accreditation and information leads them to have poor incomes and limited employment opportunities. Subsidies are also often unavailable to them due to their precarious status, preventing them from applying to housing lists. Considering these factors in addition to the experience of IPV, some may agree that an immigrant woman in this situation may already be homeless in her own home- especially considering that leaving the home to escape violence may lead to actual homelessness.

When immigrant women who had experienced IPV successfully left the relationship and found affordable housing, the many different challenges of their lives began to get resolved. As long as they have a safe place to live for themselves and their child or children, the process of settlement can truly begin. Service providers also expressed that once their clients were able to find secure housing, they saw a lot of success for the women but they were specifically referring to affordable housing, not just housing where they would possibly get evicted just a few months later. Moving into subsidized housing really helps the women feel as though they are part of something and feel that they are going to be at a standard of living where many people are and feel equal or adequate. Once they have secured adequate and affordable housing, it becomes easier to decide to be a part of an empowerment program, to go to court and get the matter of 
'parenting time' settled- these things can start falling into place and the women can take their lives into their own hands while feeling empowered to do so.

As determined through the women's experiences, the advocacy work of the service providers is extremely important to the service accessibility of immigrant women experiencing IPV and issues of housing. The establishment of relationships between support workers, counselors, staff at shelters/transition homes and housing authorities has proven to ease the shift to subsidized housing for women. Service providers are often able to act as references for the women and ensure that they would be suitable tenants. In addition, many have found ways to support immigrant women who do not have legal immigration status in applying for, and receiving, income assistance in order to be eligible for subsidized housing. It was stated in several interviews that just because someone does not have legal status, it does not mean that they do not deserve to have 'a roof over their head'.

Through the various interviews conducted, it has become clear that with a broader value on housing, concepts surrounding marginalized groups would follow suit quite quickly. If as a society we held onto the notion that housing really matters and placed it as a priority, then we would not have to meet the needs of those that are most vulnerable. If the housing first concept were widely regarded and if there were broader social housing, then it would be easier for women who are in this situation to come forward and be housed.

\section{SySTEMic CaUSES OF Housing InSECURITY AMONG IMMIGRANT WOMEN}

For an immigrant woman who has experienced IPV, almost all elements and circumstances contributing to her housing insecurity stem from systemic factors, an important indication for policies and programs that govern our society. More particularly, programs, which 
have the goal of combatting systemic factors, may likely be more successful in accommodating this population in their quest for safe and affordable housing. While programs aimed at strengthening individual capacity are also important, teaching women skills contributing to their empowerment may not sustain their lives when they have financial issues or are unable to find housing. If a woman in this situation could transition directly from the violent situation to stable subsidized housing, then she would not face a period of housing insecurity. It is then that services, programs, and advocacy are needed to address other important issues such as education or financial security.

At the core of it all, housing needs to be a priority in order for there to be an investment in social/subsidized housing. While immigration falls under federal jurisdiction, those services surrounding justice and equity are the responsibility of local and provincial governments. When it is immigrant women who make up large proportions of shelters, transition homes or subsidized housing units, federal funding must assist local and provincial levels in providing access to these populations.

While the knowledge and understanding of systems and policies was not an issue among service providers, funding proved to be a systemic barrier to providing services. Being limited in the amount of outreach hours each service provider is allotted for example created frustration for the worker as well as the client. Not only does this prevent women from receiving the amount of service that each situation requires but also prevents service providers from working to their full capacity- especially when funding for important and necessary programs is cut.

Conversely, the subsidies received by women once they have separated from their abusive partner are extremely low. Living on $\$ 600$ per month (amount received through income assistance) is next to impossible; especially considering that immigrant women who have 
experienced IPV are a vulnerable population. Often they are lacking education or the ability to get a job in one or two months and it is therefore unfair to say that their situation is temporary and that they should tough it out for the time being. There are many barriers that these women face and an increase in income assistance could at least aid them in finding suitable housing so that in turn, they are able to adjust the other elements of their lives and become contributing members of Canadian society. Also on the same topic, when an individual receives income assistance, there is a certain threshold that cannot be surpassed in terms of the income being made. In the case where an immigrant woman has worked hard to find a higher paying job and she does pass the threshold, income assistance is cut. As stated by several of the women interviewed, while they all had gratitude for the subsidies that they had received, this demotivated those who were working extremely hard to build new lives for themselves and their children.

Issues faced at the individual level can often be traced to the requirement of systemic changes. For an immigrant woman who has experienced IPV, depression as a result of the trauma may lead her to the health care system. She may seek information from friends and family in regards to her rights or Canadian laws, as she may not be familiar. Similarly, while an immigrant serving organization may be in the process of assisting her with settlement, she may disclose that she is experiencing violence from an intimate partner thus involving police in the situation. The response that is received from each of these sectors depends on the policies in place at the systemic level. Otherwise, symptoms will be identified and perhaps treated, however; the cause will be overlooked. 


\section{LIMITATIONS}

Among the challenges faced in conducting research on a vulnerable population of which many are not legally recognized in Canada, those women who do not have legal status are often less comfortable participating in the study. As such, I was unable to recruit an even number of participants falling within the categories of Canadian citizen, permanent resident, and non-status. This is important because while issues of status can be addressed to some extent, I was unable to focus more specifically on the differences between immigration status and how strongly this element affects the barriers faced by the women participants.

\section{RECOMMENDATIONS}

In order to bring forward the structural barriers surrounding access to housing for immigrant women who have experienced IPV it is important to consider the following suggestions, which are largely informed by the responses of the participants and key informants. Such recommendations include:

An increase in the amount distributed for social assistance subsidies.

With long waitlists for all types of subsidized housing, an increase in safe and affordable housing is required.

$>$ Increased funding for immigrant services (i.e. providing more multicultural workers to help combat language barriers) and services for IPV.

Upon arrival in Canada, women should be informed about programs, services, equality, rights, immigration policies, and laws. This can prevent issues of misinformation, which are common among immigrant women who are controlled by their abusers. 
Knowledge dissemination surrounding rights related to immigration status and rules regarding sponsorship breakdowns.

$>$ Public education regarding IPV in order to create public awareness and promote the empowerment of women.

$>$ Public education regarding housing markets and the various options in terms of transition homes, subsidized housing, and the rental market.

Workshops on how to fill various forms and applications (i.e. income assistance, immigration applications, housing applications etc.)

$>$ Coordination and integration among agencies in the various sectors for better understanding of the issues facing immigrant women experiencing IPV and housing insecurity. Through coordination, when a woman moves from one city to another, she will not have to go through the trauma of repeating every detail of her experiences to the various ministries involved.

While all of the participants of this research study experienced several years of difficulty with regards to leaving the violence, acquiring legal immigration status, finding the necessary support and accessing affordable housing, many expressed gratitude for the country to which they immigrated. The following statement by one of the participants embodies her feeling when asked if Canada has become home: "It definitely is, it took time but I would say that even if I was back in Pakistan, I could have never been supported the way that I was supported here and the strongest community that they gave me it's just like, I don't even have the words to describe it but I myself was not able to realize that my life has so much value. It's unbelievable, they took care of me like I'm made of glass and there was so much respect for my decisions. Every step of 
the way, wherever I am and whoever I am is because of this country honestly..." (Participant, Canadian Citizen, Pakistan). 


\section{Appendix A - Interview Guides}

\section{Interview Questions for Service Provider Participants}

\section{Information regarding organization}

- How does the organization that you work for or how do you yourself coordinate with other agencies or organizations in different sectors? Which ones?

- What kinds of services at your organization could help immigrant women experiencing or having experienced IPV and insecurity in terms of housing?

- How is the organization that you work for funded and how does this affect those who use the services offered?

- How do women generally access this organization? Do these women come to you directly for issues regarding IPV or housing insecurity?

\section{Immigrant women}

- What do you see as barriers for women to accessing services for IPV?

- What do you see as barriers for women who are trying to stabilize housing?

- How does a woman's immigration status affect either of these issues?

- What are the experiences of an immigrant woman who may be experiencing IPV? How may this affect her housing situation?

\section{Housing}

- How do you define housing insecurity/ vulnerable households?

- What is the process that an immigrant woman might go through to access affordable housing?

- What is the role of government in providing affordable housing?

\section{Policy implications}

- What are some policies that are already working well?

- What policies are not working well? Why not?

- How can these policies be changed?

- What kinds of policy implications do you think should be established?

- If there is anything else that you feel is important to share or add to this conversation, you may do so now. 


\section{Interview Questions for Immigrant Women Participants}

\section{$\underline{\text { Life }}$}

- Why did you leave your country of origin?

- Can you explain what it was like when you first arrived to Canada?

- How has your experience been in Canada? Do you or did you fear deportation?

- Do you have any family or friends living here?

- Have your experiences here in Canada been what you expected?

- How is your experience in Canada so far different from that of your home country?

\section{Service use}

- Were there any services that you used when you first arrived to Canada? How helpful were they? Are you still using any services, which ones?

- Is there an ethnic organization that you feel comfortable approaching? If not, why not?

\section{History of violence}

- Can you tell me about your relationship?

- How did you meet?

- Can you tell me about any abuse that you previously dealt with in your home?

- Who did you contact for help and how did they help you?

- What did these services or individuals do for you?

\section{Housing situation}

- What would you say makes good housing?

- Where do you consider home?

- In what type of housing are you currently living?

- What was it like finding this dwelling?

- What problems did you face in the process of finding housing?

- If you live by yourself, what does it mean for a woman of your background to be living on your own?

- Have you ever accessed any services for housing?

- Were they helpful? Why or why not?

Where do you live now?

- How do you feel about the safety of where you are currently living?

- If you left your home and went back, why did you make this decision?

\section{Current situation}

- What kinds of troubles are you still facing with daily needs?

- How could services be improved to help someone in a similar situation?

- If there is anything else that you feel is important to share or add to this conversation, you may do so now. 


\section{Appendix B - Informed Consent Form}

\section{RYERSON UNIVERSITY}

Yeates School of Graduate Studies

Graduate Studies in Immigration and Settlement Studies

Ryerson University

\section{Consent Agreement to Participate in a Research Study}

\section{In search of security: Exploring the connections between the Metro Vancouver housing market, intimate partner violence, and immigrant women.}

You are being asked to participate in a study. Before you give your consent to be a volunteer, it is important that you read the following information and ask as many questions as necessary to be sure you understand what you will be asked to do.

Investigators: Sadaf Seifi, a student in the Master's program in Immigration and Settlement Studies at Ryerson University is conducting this project, and is being supervised by Dr. Sepali Guruge, Associate Professor in the Daphne Cockwell School of Nursing at Ryerson University.

Purpose of the Study: The purpose of the study is to explore the nature and extent of housing insecurity among immigrant women who have experienced intimate partner violence (IPV). Someone who has experienced intimate partner violence (IPV) would have had threats of, and/or actual experiences of physical, sexual, psychological, or verbal abuse, by a current or former spouse or non-marital partner. This would also include situations where the individual has no freedom or liberty in their public or private life. Someone who is experiencing housing insecurity may be unable to afford suitable housing, or may be living in illegal or temporary accommodation that is insufficient in size, or does not provide any privacy.

What Participation Means: I am inviting 10-15 immigrant women from any ethnic community who have experienced IPV following their immigration to Canada and may be in a situation of housing insecurity. To participate in this study your participation will involve an individual interview of approximately 1.5 hours. With your permission, the interviews will be voice recorded and transcribed following the interview. I will also take notes during the interview to help recall some of the experiences that you have shared. You will be asked to talk about your immigration experience, your experience within the Canadian housing market, your experience with your landlord (if applicable), your experience in your neighbourhood and your experience with services that exist to support immigrant women in their housing search having experienced IPV. This will also include questions regarding your experiences of IPV.

\section{Example Interview Questions:}

- Why did you leave your country of origin? 
- Can you explain what it was like when you first arrived to Canada?

- How do you feel about the safety of where you are currently living?

- What makes you feel secure or insecure about where you live?

Potential Benefits of the Study: This study may not benefit you directly. However, we have found that many women appreciate the opportunity to share their experiences with another person in a private, confidential and safe environment. By participating, you can assist us to further understand the impact of housing insecurity on immigrant women who have experienced IPV, which can be used to inform service providers, community leaders and policy makers about improving their response to such issues.

Potential Risks or Discomfort: Your participation in completing an interview may cause some emotional discomfort. You have the right to (a) refuse to participate in the study; (b) to refuse to answer any specific questions or move to another topic; and (c) to leave the interview itself at any time. If you feel upset during the interview, I can also shift to another topic to relieve you of any discomfort. At any point during the interview, you can decide to stop, at which point you may be asked if you would like some additional support. I can arrange for you to meet with an appropriate resource if needed. You are also welcome to ask any questions from me at any time during the interview.

Confidentiality: The confidentiality of all records of participation will be upheld. You may use pseudo names if preferred. No names or identifying information will be used in any publication or presentation. All information collected and any written notes will be stored in a secure locked cabinet with access limited to my supervisor and myself. The consent forms and notes will be destroyed after 5 years.

There may be an exception to this confidentiality agreement. For example, should you by chance tell me about any suspicions or occurrences of child abuse or neglect, I am legally bound to report this to the relevant authorities.

Incentives for Participation: A small amount of $\$ 30$ will be given to you to cover the costs of childcare, transportation, and your time in taking part in the interview, which will be approximately 1.5 hours in length.

Voluntary Nature of Participation and Withdrawal: Participation in this study is voluntary. Your choice of whether or not to participate in the study will not be shared with anybody and will not influence your relations with any of the agencies serving immigrants and refugees in Canada. If you decide to participate, you are free to withdraw your consent and to stop your participation at any time during the interview without penalty. You can reconsider your participation within the first month of being interviewed and should this be your decision, your interview notes and audio recordings will be completely destroyed. If withdrawal takes place over one month after participation, removal of already collected data will not be possible as it will have already been put together with others' information. 
Questions About the Study: If you have any questions about the research now, please feel free to ask. If you have any questions about the research following the interview or you would like to receive the general results of the study in about 4-6 months, you may contact:

Sadaf Seifi, (604) 512-7043, Immigration and Settlement Studies, Ryerson University Dr. Sepali Guruge, (416) 979-5000 ext. 4964, School of Nursing, Ryerson University

If you have any questions regarding your rights as a participant in this study, you may contact the Ethics Review Board at the Office of Research Services at Ryerson University:

\author{
Research Ethics Board \\ Office of Research Services \\ Ryerson University \\ 350 Victoria Street \\ Toronto, ON \\ M5B 2K3 \\ 416-979-5042 \\ rebchair@ryerson.ca
}

\title{
Confirmation of Agreement:
}

My signature below indicates that I have read the information in this agreement, I have had a chance to ask questions about the study, and my questions have been answered to my satisfaction. My signature also indicates that I agree to take part in the study with the understanding that I may change my mind and withdraw consent to participate at any time without any repercussion. I have been given a copy of this agreement. I voluntarily consent to participate in this study.

Name of Participant Signature of Participant Date (Please print)

Your signature below indicates that you agree to have this interview audio recorded.

Name of Participant Signature Date

I confirm that I have explained the nature and purpose of the study to the participant named above. I have answered all questions.

Name of Person Signature Date 


\section{References}

Bastia, T. (2014). Intersectionality, migration and development. Progress in Development Studies, 14(3), 237-248.

BC Society of Transition Houses. BCSTH, 2010. Web. 11 Aug. 2015.

Berkel, L. A., Furlong, A. N., Hickman, A. A., \& Blue, E. L. (2005). A qualitative examination of black college women's beliefs about abuse in relationships. Professional Psychology, 36, 283-290.

Bhuyan, R., Osborne, B., Zahraei, S., \&Tarshis, S. (2014). Unprotected, unrecognized:

Canadian immigration policy and violence against women, 2008-2013. Migrant Mother's Project, 1-12.

Bilge, S. \& Dennis, A. (2010). Introduction: Women, intersectionality and diasporas. Journal of Intercultural Studies, 31(1), 1-8.

Braun, T., \& Black, J. (2003). It shouldn't take an inquest: A review of the literature examining links between domestic violence and homelessness. Calgary: Violence Information \& Education Centre.

Bryman, A. (2001). Social Research Methods. Oxford: Oxford University Press.

Burns, S. (2010). Single mothers without legal status in Canada: Caught in the intersection between immigration law and family law. Report from the YWCA Mothers Without Legal Status in Canada Project. 1-52.

City of Vancouver. (2011). Vancouver's housing and homelessness strategy 2012-2021: A home for everyone. 1-17.

Callaghan, M., Farha, L., Porter, B., Fraser, J., Harraher, N., Mulgrave, M., \& Tingley, S. (2002). Women and housing in Canada: Barriers to equality. Centre for Equality Rights in Accommodation.

Carter, T. (2005). The influence of immigration on global city housing markets: The Canadian Perspective. Urban Policy and Research, 23(3), 265-286.

Crenshaw, K. (1999). Mapping the margins: Intersectionality, identity politics and violence against women of color. Stanford Law Review, 43, 1241-1299.

Creswell, J. W. (2013). Qualitative Inquiry \& Research Design: Choosing From Five Approaches. $3^{\text {rd }}$ edition. Los Angeles: Sage. 
Elliott, R. \&Timulak, L. (2005). Descriptive and interpretive approaches to qualitative research. In A handbook of research methods in clinical and health psychology, Edited by: Miles, J. and Gilbert, 147-159.

Federation of Canadian Municipalities. (2011). Starting on solid ground: The municipal role in immigrant settlement. 1-28.

Francis, J., \& Hiebert, D. (2013). Shaky foundations: Refugees in Vancouver's housing market. The Canadian Geographer, 58(1), 63-78.

Fiedler, R., Schuurman, N., \& Hyndman, J. (2006). Hidden homelessness: An indicator-based approach for examining the geographies of recent immigrants at-risk of homelessness in Greater Vancouver. Cities 23(3), 205-216.

Gillard, G. (2014). Fostering inclusion for newcomers to Ottawa: A CHRA session case study. The Canadian Housing and Renewal Association. Ottawa, ON.

Guruge, S. (2012). Nurses' Role in Caring for Women Experiencing Intimate Partner Violence in the Sri Lankan Context. ISRN Nursing, 1-8.

Guruge, S. \& Khanlou, N. (2004). Intersectionalities of influence: Researching the health of immigrant and refugee women. Canadian Journal of Nursing Research, 36(3), 32-47.

Guruge, S., Tiwari, A., \& Lucea, M.B. (2010). "International perspectives on family violence” in Violence and Nursing Practice, J. Humphreys and J. Campbell, Eds., Springer, New York, NY, USA, 2nd edition.

Hiebert, D., Germain, A., Murdie, R., Preston, V., Renaud, J., Rose, D., ...Murnaghan, A. M. (2006). The housing situation and needs of recent immigrants in the Montréal, Toronto, and Vancouver CMAs: An overview. Canada Mortgage and Housing Corporation. Vancouver, B.C.

Hill, D. E. (2011). Moving forward: Advancing the economic security of immigrant women in Canada- A discussion paper. Women's Economic Council.

Hochreiter, S. (2014). Race, class, gender? Intersectionality troubles. Journal of Research in Gender Studies, 4(2), 1-7.

Hulchanski, J. D. (1997). Immigrants and access to housing: How welcome are newcomers to Canada? Summary of Keynote Presentation to the "Housing and Neighborhoods" Workshop. 212.

Hulchanski, J. D. (2005). Re-thinking Canada's housing affordability challenge. Discussion paper. Centre for urban and community studies.

Hyman, I., Forte, T., Du Mont, J., Romans, S.E., \& Cohen, M.M. (2009). Help-seeking behavior for intimate partner violence among racial minority women in Canada. Women's Health Issues, 
19(2), 101-108.

Hyman, I., Mason, R., Guruge, S., Berman, H., Kanagaratnam, P., Manuel, L. (2011). Perception of factors contributing to intimate partner violence among Sri Lankan Tamil immigrant women in Canada. Health Care for Women International, 32, 779-794.

Kanagaratnam, P., Mason, R., Hyman, I., Manuel, L., Berman, H., Toner, B. (2012). Burden of womanhood: Tamil women's perceptions of coping with intimate partner violence. Journal of Family Violence, 27, 647-658.

Kaur, H., Porteous, T., Kamaljit, K. L., Ruebsaat, G., Bassi, B., Rashid, H., ...Duder, C. (2012). Immigrant Women's Project: Safety of immigrant, refugee and non-status women. Ending Violence Association of BC, MOSAIC, \& Vancouver \& Lower Mainland Multicultural Family Support Services Society.

Kelly, U. (2011). Theories of intimate partner violence: From blaming the victim to acting against injustice, Intersectionality as an analytic framework. Advances in Nursing Science, 34(3), 29-51.

Menjivar, C. \& Salcido, O. (2002). Immigrant Women and Domestic Violence: Common Experiences in Different Countries. Gender and Society, 16(6), 898-920.

Ministry of Children and Family Development British Columbia. (2010). Best practice approaches: Child protection and violence against women. 1-68.

Miraftab, F. (2000). Sheltering refugees: The housing experience of refugees in metropolitan Vancouver, Canada. Canadian Journal of Urban Research, 9(1), 1-17.

Morash, M., Bui, H., Zhang Y., \& Holtfreter, K. (2007). Risk factors for abusive relationships: A study of Vietnamese American immigrant women. Violence Against Women, 13, 653-675.

Ontario Domestic Violence Advisory Council. (2009). Transforming our communities: Report from the domestic violence advisory council for the Minister responsible for women's issues. 997.

Paradis, E., Novak, S., Sarty, M., \& Hulchanski, J. D. (2008). Better off in a shelter? A year of homelessness \& housing among status immigrant, non-status migrant, \& Canadian-born families. Centre for Urban and Community Studies Cities Centre, University of Toronto. Research Paper 218.

Saltzman, L. E., Fanslow, J. L., McMahon, P. M., \& Shelley, G. A. (2002). Intimate partner violence surveillance: Uniform definitions and recommended data elements, version 1.0.

Shields, S. A. (2008). Gender: An intersectionality perspective. Sex Roles, 59, 301-311. 
Rummens, J. A. (2003). Conceptualizing identity and diversity: overlaps, intersections, and processes. Canadian Ethnic Studies, 35(3), 10-25.

Tjaden, P. \& Thoennes, N. (2000). Extent, nature and consequences of intimate partner violence: Findings from the National Violence Against Women Survey. National Institute of Justice and the Center for Disease Control and Prevention.

Thorne, S., Reimer-Kirkham, S, \& O'Flynn-Magee, K. (2004). The analytic challenge in interpretive description. International Journal of Qualitative Methods, 3(1), 1-21.

Thurston, W., Clow, B., Este, D., Gordey, T., Haworth-Brockman, M., McCoy, L... \& Smith, J. (2006). Immigrant women, family violence, and pathways out of homelessness. Report for the National Secretariat on Homelessness.

Thurston, W., Roy, A., Clow, B., Este, D., Gordey, T., Haworth-Brockman, M., \& McCoy, L. (2013). Pathways Into and Out of Homelessness: Domestic violence and housing security for immigrant women. Journal of Immigrant and Refugee Studies, 11, 278-298.

Vickers, J. (2002). Methodologies for scholarship about women. In V. Dhruvarajan \& J. Vickers, Gender, race, and nation: A global perspective. Toronto: University of Toronto Press.

Wachsmuth, D. (2008). Housing for immigrants in Ontario's medium-sized cities. Canadian Policy Research Networks Research Report.

Worden, A. P., \& Carlson, B. E. (2005). Attitudes and beliefs about domestic violence: Results of a public opinion survey: II. Beliefs about causes. Journal of Interpersonal Violence, 20, 12191243. 